\title{
Las rutas de las ideas: «cuestión social», feminismos y trabajo femenino
}

\author{
por \\ Mirta Zaida Lobato \\ Universidad de Buenos Aires
}

\begin{abstract}
En este artículo analizo las voces que permiten desentrañar la configuración de un conjunto de preocupaciones políticas y sociales cuyo núcleo está constituido por lo que hacen o dejan de hacer las mujeres que trabajan, y sobre los modos en que se conformaron las rutas de las ideas sobre feminismos y cuestión social. Me concentro en particular en las figuras de Ernesto Quesada, un intelectual de la generación del 90, en Elvira López, autora de la primera tesis sobre el movimiento feminista realizada en 1901 en la Facultad de Filosofia y Letras de la Universidad de la Universidad de Buenos Aires, y en Carolina Muzilli militante socialista. Esto me permite pensar ámbitos de actuación y modos de intervención heterogéneos así como el uso y difusión de la palabra escrita alrededor de las ideas sobre problemas sociales.
\end{abstract}

Palabras Clave: Feminismos; Cuestión social; Trabajo femenino; Historia social; Historia cultural.

El mundo de trabajo urbano y rural, sus organizaciones gremiales, las protestas, la prensa obrera, las instituciones laborales, las ideologías del movimiento obrero, el rol del estado, los contenidos de la cuestión social (la educación, la salud, la protección y la desprotección laboral) han sido examinados con matices y con mayor profundidad para algunos periodos históricos. Asimismo, la relación género-trabajo ha sido ampliamente estudiada desde las perspectivas feministas y/o de género, especialmente el trabajo femenino asalariado en fábricas y talleres, aunque una parte significativa de las labores femeninas se desplegaban en la casa propia. Sin embargo hay algunas zonas aún poco exploradas, y es el modo en que las nociones relacionadas con «lo 
social», con las ideas de solidaridad y protección de los trabajadores — sean ellos varones o mujeres, de diferentes edades y de diversas procedencias regionales - circularon entre América Latina y Europa, entre los distintos países de la región y al interior de los estados nacionales. De la misma manera queda mucho por hacer en relación con la conformación de una cultura visual vinculada con el trabajo y la cuestión social, con el complejo territorio de la circulación de imágenes.

En estas páginas me acercaré al modo en que las ideas sobre los problemas sociales, y específicamente sobre la cuestión de la mujer trabajadora, circularon en la Argentina desde fines del siglo XIX y principios del XX, entendiendo a su vez que esos saberes tienen el poder de organizar visiones del mundo en sectores más amplios de la sociedad. Como he señalado en otros textos ${ }^{1}$, «cuestión social» $\mathrm{y}$ «cuestión de la mujer» estuvieron estrechamente imbricadas y se fueron conformando ciertas nociones sobre la condición femenina, el trabajo y sus características que se reforzaron en las primeras décadas del siglo XX. Las mujeres fueron consideradas importantes para la salud de la raza y de la nación y, por eso, se valorizó su condición de reproductora más que de productora de bienes o sus capacidades y habilidades manuales e intelectuales. Se configuró la idea de la «pobre madre obrera» que había que proteger frente a los abusos de los patrones y la «explotación del capital». Mujer y trabajo se constituyeron como una díada problemática que había que estudiar y analizar y, para ello, el mundo fue convertido en un taller de observación y en una fuente de soluciones.

En ese sentido, las miradas problemáticas sobre el trabajo femenino fueron el resultado tanto de la visibilidad que este fue adquiriendo en la sociedad argentina, como de las tensiones que se generaban entre trabajo y función reproductiva, así como el privilegio que se atribuía al rol genético de la mujer, en tanto ella tenía la responsabilidad de conservar, reproducir y mejorar a los habitantes de la Nación. De modo que intento responder al interrogante sobre los ámbitos de actuación, sobre las voces que permiten desentrañar la configuración de un conjunto de preocupaciones políticas y sociales cuyo núcleo está constituido por lo que hacen o dejan de hacer las mujeres que trabajan, y sobre los modos en que se conformaron las rutas de las ideas pensando que se trata de un edificio complejo, susceptible de ser analizado a través de la palabra impresa (libros, folletos), de imágenes (fotografías, postales, pinturas) y de algunas figuras que privilegiaron la enunciación de los problemas relacionados con la condición femenina.

Si esto es así las respuestas son múltiples, pues intelectuales, militantes, artistas, escritores y el propio Estado en cualquiera de sus niveles (municipal,

1 Lobato, 2000. 
provincial y nacional) estudiaron, denunciaron y problematizaron la presencia de las mujeres en diferentes espacios de actuación. Debido a la complejidad y heterogeneidad de los discursos y de la diversidad de esferas de intervención, recorto, en este artículo, algunos ámbitos desde donde se produjo la enunciación sobre la condición femenina y, sobre todo, del trabajo femenino como una cuestión importante para el Estado, la nación y la sociedad. Me concentro en las figuras de Ernesto Quesada, un intelectual de la generación del 90, en Elvira López, autora de la primera tesis sobre el movimiento feminista realizada en 1901 en la Facultad de Filosofía y Letras de la Universidad de Buenos Aires, y en Carolina Muzilli, militante socialista. Esto me permite pensar ámbitos de actuación y modos de intervención heterogéneos, así como el uso y difusión de la palabra escrita alrededor de las ideas sobre problemas sociales.

El telón de fondo para que la cuestión de la mujer adquiriera densidad problemática fueron las transformaciones de la sociedad, la economía y la política en la Argentina con la ampliación de las actividades productivas, la generalización del trabajo asalariado, la creciente separación entre trabajo por un salario (fuera del hogar) en el mundo urbano y el trabajo doméstico, más orientado al quehacer y menos regulado por las agujas del reloj. En ese proceso fue también tomando forma la codificación y regulación de las relaciones entre las personas y de avance del imperio del Estado sobre el conjunto de la población, estableciendo distintas normas y regulaciones. Paralelamente los trabajadores se organizaron y reclamaron mejores condiciones de vida y de trabajo, y desde la perspectiva de las organizaciones gremiales la mujer fue tanto la víctima principal de la «explotación capitalista» como la «competidora desleal», responsable de la falta de organización de las huestes obreras. Pero lo más importante desde mi punto de vista es que el mundo laboral y el de las organizaciones gremiales fue constituido como primordialmente masculino $\mathrm{y}$, por eso, se fueron conformando y afianzando las ideas de subordinación y complementariedad del trabajo femenino.

\section{CULTURA CIENTÍFICA Y MODERNIDAD: LAS MUJERES EN EL PENSAMIENTO SOCIOLÓGICO DE ERNESTO QUESADA}

Las tensiones de la modernidad (conflicto social, cosmopolitismo, identidad nacional) fueron un tema recurrente en el pensamiento de quienes habían compartido una educación privilegiada y se vinculaban con el poder. Ernesto Quesada fue una de esas figuras que, como señala Terán ${ }^{2}$, tenía ojos educados

\footnotetext{
2 Terán, 2000: 209.
} 
para pensar los fenómenos urbanos de la modernidad. Conocía el mundo porque había seguido a su padre por Brasil, Estados Unidos, España, México, Alemania, Austria y Rusia, había estudiado en París, y compartía con otros políticos e intelectuales la idea sobre el carácter científico de las ciencias sociales. Fue profesor en la universidad de Buenos Aires y, desde ese lugar, irradió formas de pensar y analizar diversas cuestiones vinculadas con la cuestión social ${ }^{3}$. Formó parte de un grupo más amplio, pero no tan numeroso, que desde la cátedra universitaria le dio legitimidad a las cuestiones sociales en ese ámbito y también fuera de él. Se convirtió, como señala Altamirano ${ }^{4}$ en una autoridad cultural cuyo fundamento era la investigación académica. Entre los temas que la virada del siglo XIX al XX puso en un lugar destacado del debate intelectual estuvo la "cuestión femenina» y reclamó un atento estudio del problema.

Viaje y estudio estuvieron presentes a lo largo de su vida. Ernesto Quesada era miembro de una familia acomodada y distinguida y el apellido está asociado con la vida política e intelectual en el período que aquí se privilegia ${ }^{5}$. Los ámbitos de sociabilidad de los miembros de la elite son ampliamente conocidos: a través del esparcimiento en los salones, de los bailes, de las visitas a las estancias, la participación en clubes - como el del Progreso- se fueron afianzando contactos personales y sociales. Los ámbitos universitarios eran también lugares privilegiados para el desarrollo de vínculos importantes, y en sus aulas se compartían lecturas y se conformaban lazos de afinidades intelectuales, políticas y afectivas. Los viajes de estudio y hasta las relaciones personales y amorosas constituyen el entramado intelectual de una persona. Como ha señalado Sandra Carreras ${ }^{6}$, Quesada estableció estrechos lazos con Alemania y con el pensamiento de Oswald Spengler, con el apoyo seguramente imprescindible de Leonore Deiters con quien vivió hasta su muerte. Por otra parte, Spengler había sido marcado por la lectura de Ernst Haeckel, autor que tuvo una amplia difusión en la Argentina ${ }^{7}$.

${ }^{3}$ En 1904 Ernesto Quesada inauguró la cátedra de sociología en la Facultad de Filosofía y Letras de la Universidad de Buenos Aires, y a partir de 1907 enseñó también en la Facultad de Derecho de la Universidad de La Plata (Zimmermann, 1995: 84-89). En 1915 presidió la sección sobre trabajo, previsión y asistencia social del Congreso Americano de Ciencias Sociales en la que participaban Alfredo Palacios y Horacio Rivarola entre otros. Revista Argentina de Ciencias Políticas, XX (1915): 536-547. Por otra parte, su conferencia «La cuestión obrera y su estudio universitario» fue publicada en el Boletín del Departamento Nacional del Trabajo, 1/1 (1907), y como folleto por Librería Menéndez, Buenos Aires, 1907.

${ }^{4}$ Altamirano, 2004: 33.

${ }^{5}$ Buchbinder, 2012: 13.

${ }^{6}$ Carreras, 2008.

7 Terán, 2004 y 2000. Barrancos, 1996. 
En 1898 Quesada colocó en la mesa de debate el tema de la desigualdad femenina cuando le habló a una audiencia, mayoritariamente femenina, que había organizado una exposición de sus habilidades (bordados, encajes y telas pintadas). Él pensaba que a pesar de todas las reformas legislativas, y como consecuencia de ellas, se había consagrado la «injusta desigualdad de la mujer (...) sometiendo a aquella a perpetua tutela: de los padres primero, de los esposos, y de los jueces por último» ${ }^{8}$. Consideraba también que la exposición constituía un marco adecuado para promover la discusión sobre la condición laboral, educativa y social de las mujeres, pues se imponía la solución del problema.

Ahora bien, ¿cuál es en realidad dicho problema? En primer lugar y desde su perspectiva, que no todas las mujeres se casan y en consecuencia buscan otro ideal (el tema del hogar y los hijos es crucial en muchos sentidos); en segundo término, que el crecimiento del consumo hace que la actividad de los hombres sea insuficiente para sostener una familia (lo que contribuye a consolidar la idea del varón proveedor); por último, que las mujeres solteras se ven forzadas a obtener los recursos para satisfacer las necesidades de la vida (el trabajo como necesidad) ${ }^{9}$. De modo que las exigencias de la vida material impusieron como solución la admisión de las mujeres en los talleres, aunque con salarios inferiores. Para Quesada el diagnóstico y la solución eran claros: si la mujer dependía del hombre, si estaba obligada a trabajar, si no era educada era un imperativo modificar ese estado de cosas.

La cuestión social, que la visibilidad del mundo del trabajo volvía ineludible, y la cuestión de la mujer, que convertía el trabajo femenino fuera del hogar en un problema, porque esta era empujada al taller, lo que afirmaba la desigualdad entre los sexos en todos los órdenes, se unía con una tercera dificultad que emerge del texto de Quesada: la cuestión nacional. Era necesario definir un sujeto nacional en un país profundamente transformado por el fenómeno inmigratorio, en particular en la región litoral argentina, y las mujeres jugaban un rol importante en esa enunciación ${ }^{10}$.

\footnotetext{
${ }^{8}$ Quesada, 1899: 13.

9 Dice Quesada en uno de los pasajes de la conferencia: «El trabajo de la mujer es, pues, un problema en este país; no deja, a la destituida de fortuna hereditaria, más solución que el matrimonio o la miseria, si el vicio no la arrebata». Ibidem: 30 .

${ }^{10}$ Cuestión nacional, cuestión social y cuestión de la mujer aparecen planteados como partes de un problema común en Lobato (Lobato, 2000), los nexos entre cuestión social y feminismos en Nari, (Nari, 2000 y 2005). La cuestión nacional ha sido ampliamente analizada en los textos de Oscar Terán y Carlos Altamirano, pero sin incorporar la dimensión de género en sus estudios e interpretaciones.
} 
Con esta conferencia Ernesto Quesada le hablaba a un público femenino que venía bregando por el reconocimiento de derechos civiles iguales a los que gozaban los hombres y, como él era un observador (y consumidor) atento de los saberes modernos, no pudo eludir las referencias al feminismo. Señala así la transformación doctrinaria que significó la aparición de los escritos de Mary Wollenstonecraft, así como la formación de clubes y la edición de periódicos feministas en la convulsionada Europa del año 1848, o la organización de congresos feministas y exposiciones universales como las de París en 1889 y Chicago en 1892. Entonces los clubes, las asociaciones, la prensa y los congresos permitieron la circulación de las ideas feministas. Además, la cita es relevante en tanto podemos imaginar que la Vindicación de los derechos de la mujer, un texto de 1792 donde se planteaba la disyuntiva entre igualdad y diferencia, dos tópicos articuladores de los debates feministas posteriores, comenzó a circular hacia fines del siglo XIX en Buenos Aires.

Veinte años más tarde, Ernesto Quesada volvió sobre el tema en una conferencia dada el 21 de enero de 1920 en el Consejo Nacional de Mujeres, donde retomaba los argumentos de su conferencia de 1898 y planteaba cuestiones relacionadas con la igualdad civil pero, sobre todo, señalaba los límites del feminismo o, según sus palabras, sus debilidades: la idea de liberación o independencia de la mujer, el uso del concepto de «mujer creadora» y la consideración del feminismo como negación de la esencia de la feminidad ${ }^{11}$. Para él, la libertad es individual, la libertad económica y política es colectiva, y la función de la mujer es realizarse en la maternidad. Opone la fecundidad a la creación intelectual y considera que en su desenvolvimiento el éxito de una afecta a la otra. Expresaba también: «si el movimiento feminista satisfacía la idea fundamental de lo femenino, no quedando ni un detalle que no esté a su modo glorificado, entonces solo debe propender - pues trae consigo el amor, desde que nace, cosido al corazón - a que la mujer sea madre, en el sentido literal y figurado: el principio de la fecundidad y el de la conservación de la vida» ${ }^{12}$. Las nociones de amor y cuidado como parte constitutiva del sujeto femenino aparecen claramente enunciadas. Estas ideas estaban asociadas con determinadas actividades laborales, por ello reafirma que las mujeres desempeñan las mejores funciones cuando sus actividades se relacionan con los cuidados maternales: la beneficencia pública, la asistencia y educación de los niños o el cuidado de enfermos. Lo que hoy llamamos la ética del cuidado. Para él si las mujeres entraban a fábricas y talleres o a las

${ }^{11}$ Quesada, 1920: 3-26.

12 Ibidem: 18. 
tiendas como empleadas lo hacían principalmente preocupadas por la vida e insistía en que la «misión específicamente femenina» era «la conservación de la vida», esto era lo visible y evidente aunque la mujer participara en la vida pública. El paso entonces entre la maternidad física y la maternidad social era muy pequeño.

\section{LA UNIVERSIDAD: UN ÁMBITO PARA LA PRODUCCIÓN Y DIVULGACIÓN DE IDEAS}

En 1901 Elvira López presentó la tesis titulada El movimiento feminista para optar al grado de doctora en Filosofía y Letras de la Universidad de Buenos Aires. Fueron sus padrinos los doctores Rodolfo Rivarola y Antonio Dellepiane. El primero era catedrático titular en Psicología y el segundo en Historia Universal. Rodolfo Rivarola fue años más tarde el fundador de la Revista Argentina de Ciencias Políticas que se editó entre 1910 y $1928^{13}$. Destaco esta conexión pues la revista bajo su dirección no solo se preocupó por temas relacionados con el régimen republicano, por el federalismo, el sufragio o la división de poderes, sino también por la legislación social y la llamada «cuestión obrera». En sus páginas tuvieron cabida los debates sobre los derechos civiles de las mujeres, sobre el sufragio femenino y sobre legislación laboral. Como señala Darío Roldán ${ }^{14}$ en ella participaban abogados que buscaban intervenir públicamente, pero además vincular la cátedra universitaria con la conformación de una opinión pública. Esa práctica incluía los problemas relacionados con la condición femenina en el plano civil, político y social.

La revista se planteaba como «órgano de ideas y estudios de interés general y de libre discusión, evitando todo peligro sectario, excluyente o partidista ${ }^{15}$. Además incluía comentarios de libros lo que favorece el conocimiento de las publicaciones sobre temas diversos. Ernesto Quesada escribió en esta revista en numerosas oportunidades. Además las conferencias y los contenidos de los cursos dados por Rivarola, Quesada e incluso el español Adolfo Posada se publicaban tanto en las revistas más especializadas como en la prensa comercial.

En la Facultad de Filosofía y Letras, creada a fines del siglo XIX, Rodolfo Rivarola fue profesor en la cátedra de Ética y Metafísica y, como señala María

\footnotetext{
${ }^{13}$ Para un estudio de las dimensiones políticas que aparecen en la revista véase Roldán (Roldán, 2006) y Botana (Botana, 1985).

14 Darío Roldán, 2006: 17-18.

15 Revista Argentina de Ciencias Politicas (RACP), V/25 (1912): 5.
} 
Spadaro ${ }^{16}$, introdujo a Kant en sus cursos. Él fue uno de los consejeros de Elvira López, la primera mujer que obtuvo el título de doctora en esta institución de educación superior. De modo que para pensar las rutas del feminismo y del pensamiento sobre la cuestión de la mujer trabajadora un paso importante es revisar un momento «fundacional» de la reflexión académica sobre el tema como es el de principios del siglo $\mathrm{XX}^{17}$.

El movimiento feminista es el título de la tesis de López que tiene un objetivo claro: analizar el desarrollo de ese movimiento. Las metas que se propone abordar pueden convertirse, aún hoy, en un programa de investigación. Analiza la evolución y desarrollo de los feminismos en varias naciones europeas (Estados Unidos, Canadá, África, India y Argentina) y plantea la importancia de la instrucción de la mujer para transformarse ella misma y a la sociedad. Presta atención a la condición femenina a lo largo del tiempo, la educación, la formación profesional, los derechos (económicos, civiles y políticos). Solo un capítulo, el XV, está destinado a examinar la peculiar situación en Argentina, y el último refiere a los congresos feministas internacionales ${ }^{18}$.

Por la época en que Elvira y Ernestina López iniciaron sus estudios, la presencia femenina en las aulas universitarias era excepcional. La Facultad de Filosofía y Letras había sido creada en 1896 y, pocos años después, solo unas pocas mujeres habían obtenido sus diplomas en las distintas disciplinas que en ella se cursaban. En el año en que López defendió su tesis otras tres jóvenes hicieron lo mismo ${ }^{19}$. Elvira López eligió un campo de estudio poco frecuentado por las mujeres a principios de siglo en nuestro país: la filosofía. A fines del siglo XIX era más frecuente que las aulas y pasillos de la Facultad de Medicina albergaran a unas pocas mujeres como Cecilia Grierson y Elvira Rawson, quienes se graduaron en 1889 y 1892 respectivamente.

Independientemente de la disciplina que eligieran, las universitarias de esta época compartían la experiencia de ingresar a territorios profesionales que se afianzaban bajo el dominio de los varones. Todos ellos eran hombres prominentes de la elite. Solo como ejemplo basta decir que el decano de la Facultad de Filosofía y Letras era Miguel Cané y académicos titulares eran Indalecio Gómez, Joaquín V. González, Rafael Obligado, Estanislao Zeballos

\footnotetext{
16 Spadaro, 2002: 93.

17 Barrancos, 2002: 91. Spadaro, 2002: 93.

18 López, 1901. Sus padrinos de tesis fueron los Doctores Rodolfo Rivarola y Antonio Dellepiane, Lobato, 2002.

19 Ellas fueron María Atilia Canetti, Ana Mauthe, y Ernestina López (hermana de Elvira) Las tesis están disponibles en la Facultad de Filosofía y Letras de la Universidad de Buenos Aires.
} 
y el mismo Rivarola entre otros. Algunos de ellos formaban parte del cuerpo docente e integraban las «mesas de tesis» como García Mérou, García Velloso, Lafone Quevedo, Matienzo. Joaquín V. González fue quien presentó la propuesta de sanción de un Código del Trabajo en 1904.

En la tesis es posible identificar las lecturas que fundamentan la importancia de la «justicia distributiva» de la que eran partidarias las feministas. Ella identifica la existencia de una «causa de la mujer» que la rescate de su situación de subordinación, ya que le permitiría «ganar su subsistencia con las mismas facilidades que el hombre (...) para que no se vea lanzada en las vías de la perdición a que muchas empuja la miseria ${ }^{20}$. Para ella el trabajo es preferible a la «perdición», y en este sentido comparte un modo extendido de pensar el trabajo femenino como necesidad y en constante tensión con la moral. Trabajo y virtud podían convertirse en antitéticos ${ }^{21}$.

Según sus palabras, las mujeres no están solas en sus reclamos de mejoras: «pues se han declarado en su favor publicistas, sociólogos y filósofos de la talla de Stuart Mill, que ha merecido ser llamado el piloto del siglo» ${ }^{22}$. No es vano resaltar la cita, pues ella opera en este texto y en tantos otros como reconocimiento de una autoridad que legitima el saber. Elvira López está diciendo que la solución de la situación de inferioridad de las mujeres necesita de la eliminación de las restricciones y que no se admita «poder ni privilegio para unos ni incapacidad para otros». Como dice Spadaro ${ }^{23}$, su idea de justicia se vincula estrechamente con el concepto de igualdad aunque hay matices y no todos sus significados pueden ser aceptados o rechazados. Pero la igualdad está en permanente tensión con la diferencia, por eso sostiene que «Es preciso que la mujer pueda practicar todas aquellas profesiones que no sean contrarias a su dignidad y a su sexo. La mujer debe ser siempre mujer; no saliéndose de su esfera es como puede estar segura de conseguir el triunfo de su causa» ${ }^{24}$.

Según la tesista, las opiniones de los «filósofos y escritores [...] por la novedad o por la resonancia que han tenido, no pueden ser olvidadas» ${ }^{25}$. Otra vez da cuenta de sus lecturas Proudhon, Comte, Michelet, Spencer, frecuentemente mencionados y estudiados en la Argentina. Pero también cita a Concepción Arenal a quien reinterpreta ya que destaca la importancia de una educación que vaya más allá de la conveniencia para el hombre y la familia.

\footnotetext{
${ }^{20}$ López, 1901: 17.

${ }^{21}$ Lobato, 2000; 2005; 2007.

${ }^{22}$ López, 1901: 17.

23 Spadaro, 2002: 96.

${ }^{24}$ López, 1901: 20.

25 Ibidem: 17.
} 
Se podría afirmar que el tema compartido con la pensadora española es el papel fundamental que se otorga a la educación e instrucción de la mujer. Para López «las jóvenes necesitan recibir una educación tal que les permita revelar sus facultades especiales, y a las que no son ricas, elegir una carrera, para ponerse, llegado el caso, al abrigo de la miseria» ${ }^{26}$. El mundo es su laboratorio de observación, allí están las experiencias, los estudios, las lecturas, las formas en que se resuelven los problemas. Pero no es mera copia, se trata de una reflexión localizada (situada) donde las marcas de la autoctonía (el contexto argentino, la herencia española) se comparan para mostrar las coincidencias y las disidencias ${ }^{27}$.

En la tesis se advierte también una ruta posible para el feminismo del siglo XVIII inglés y la figura es, como en Quesada, Mary Wollstonecraft. El derecho a la educación («una instrucción sólida y completa»), al trabajo y a la libertad política son los reclamos y, posiblemente por eso, califica a la «Reivindicación de la mujer» (sic) como una obra «notable y adelantada para la época». Pero también existen otros caminos pues la idea feminista se irradia de Suecia y Noruega, de Finlandia, donde se han realizado «los mayores progresos», de la poco conocida Bulgaria y, sin duda, de Francia. En el territorio americano el camino viene del norte, de los Estados Unidos.

Sobre el trabajo femenino señala Elvira López que es necesario para la sociedad de su época, y destaca también la insuficiencia del salario, situación reconocida también por Ernesto Quesada y frecuentemente denunciada por la prensa gremial y la anarquista y socialista. Escribe que «los oficios como la confección de vestidos, lencería y costura desbordan de trabajadores y sus salarios son insuficientes», y que «las pobres costureras ganan para no morirse de hambre». Realiza también un inventario de la situación de las obreras «en el viejo mundo» y concluye, una vez más, que los salarios son siempre inferiores a los de los hombres ${ }^{28}$. Esta constatación y su pervivencia hasta el presente obligan a pensar las razones de la persistencia de un patrón de desigualdad y discriminación.

Además, identifica claramente que las mujeres se desempeñan por un lado en la fábrica o el taller y por otro en el trabajo a domicilio. Sobre este último señala que «Para las que trabajan en sus hogares la situación no es mucho mejor; las condiciones higiénicas son generalmente peores que las del taller, su labor se prolonga indefinidamente en las horas de la noche

26 Ibidem: 20.

${ }^{27}$ Las palabras 'reflexión localizada' y 'autoctonía' las tomo de María Luisa Femenías (2005: 10) en su reflexión sobre los feminismos iberoamericanos.

28 Todas las citas están tomadas de López, 1901: 202-241. 
sin control ninguno, y los hijos son sacrificados muchas veces para ayudar a las madres; por todas estas consideraciones, se habla a veces, de suprimir el trabajo a domicilio; sin embargo son generalmente las más débiles las que lo realizan [...]; por consiguiente una medida radical como la que indicamos antes, vendría a herir a las más débiles, a las más necesitadas, condenándolas a perecer». Aunque el trabajo fabril no puede ser desdeñado ella está más interesada en describir la incorporación de las mujeres en las profesiones liberales y en el comercio, actividades que considera más apropiadas para ellas.

Finalmente quiero destacar que el análisis de los congresos feministas internacionales permite pensar el significado que ellos tienen para la circulación de ideas, conceptos y prácticas. La realización de congresos nacionales e internacionales fue (y es) una base importante de la propaganda feminista, pero no solo de ella. Es conocido el proceso mediante el cual los y las congresistas opinan, presentan investigaciones y tejen redes de afinidades. En muchos de los congresos feministas de fines del siglo XIX analizados por Elvira López los temas tratados están estrechamente relacionados con los tópicos de la cuestión social: «mejorar la suerte de los desvalidos y asegurar la protección de los débiles», pero también temas relacionados con la filantropía, la moral, la educación, la vejez, la protección y la legislación. En esas reuniones se leían trabajos sobre una enorme variedad de temas, pero a mí me interesa destacar aquellos que se ocupaban de la legislación especial del trabajo femenino, los salarios, el hogar como taller, los sindicatos obreros y la formación de las cajas de asistencia sobre maternidad ${ }^{29}$.

La tesis de Elvira López fue presentada nueve años antes de la realización del Congreso Femenino Internacional organizado por la Asociación de Universitarias Argentinas, y para entonces sus ideas probablemente se habían afirmado. Formó parte del grupo de organizadoras del congreso, pues aparece como «personal» de la segunda sección destinada a debatir temas relacionados con derechos. Integraban esa comisión otras militantes feministas de la época como Elvira Rawson de Dellepiane, Julieta Lanteri, Petrona Eyle y Sara $\mathrm{Justo}^{30}$. Además presentó una comunicación sobre «las industrias nacionales femeninas en las escuelas profesionales».

${ }^{29}$ Elvira López analiza el Congreso Internacional de las Obras e Instituciones Femeninas (París, 1889), el de Londres de 1899, el Congreso Internacional a favor del Desarme y de la Paz (París, 1900), los congresos contra la «trata de blancas» de Londres y Bruselas (1900) y el Congreso internacional de las madres de Washington de 1898.

${ }^{30}$ Para un análisis de las reivindicaciones más amplias de las mujeres en el Primer Congreso Femenino Internacional y el Primer Congreso Patriótico de Señoras, véase Barrancos, 2001. 
El lugar de la formación profesional estaba en debate y ella consideraba que en las escuelas establecidas en las provincias debían adueñarse de los conocimientos de las «industrias locales», como el tejido de ponchos y mantas, el trenzado de la paja y del cuero y la conservación de frutas, en tanto constituyen «los medios de vida de casi todas las mujeres de la clase pobre», para mejorarlos y enseñarlos nuevamente prestando así una doble contribución: «a las mujeres que necesitan vivir de una labor y al mismo tiempo al progreso de las industrias nacionales ${ }^{31}{ }^{3}$. Fue también una de las oradoras en la sesión de clausura, la otra fue la delegada por el Paraguay la doctora Serafina Dávalos, una reconocida militante feminista de ese país. Ella denunció en su discurso la desigualdad de los salarios femeninos y masculinos como consecuencia de la ausencia de una reglamentación adecuada. La relación equidad / democracia aparece claramente expresada cuando considera que la situación de inequidad continuará «hasta que las mujeres tomen participación activa en la organización política del país y en las marchas de los gobiernos, velando por el interés de su sexo» ${ }^{32}$. El tema de la desigualdad salarial como parte de un mundo laboral inequitativo se denunció abiertamente y se votó una resolución que decía: «El Congreso Femenino Internacional considerando que el trabajo femenino peor retribuido y más extenuante para la mujer es el que realiza en su domicilio, hace votos para que las asociaciones femeninas se preocupen seriamente de esta cuestión, a fin de mejorar cuanto antes la situación de dichas obreras» ${ }^{33}$.

Las actas del evento constituyen una fuente importante para pensar los vínculos que se generaban en ese ámbito, así como es una evidencia sobre la constitución de redes de solidaridad y afinidad política e intelectual ${ }^{34}$. De acuerdo con los objetivos del Congreso ellas querían «establecer lazos de unión entre todas las mujeres del mundo», «vincular a las mujeres de todas las posiciones sociales a un pensamiento común», «modificar prejuicios, tratando de mejorar la situación social de muchas mujeres». En la época del

${ }^{31}$ Primer Congreso Femenino Internacional - Historia, Actas y Trabajos, Imprenta Ceppi, Buenos Aires, 1911. Recientemente fueron editadas por la Universidad Nacional de Córdoba, Córdoba, 2008. Las citas corresponden a esta última edición:123.

32 Ibidem: 494-495.

${ }^{33}$ Idem.

${ }^{34}$ En las crónicas sobre el Congreso Americano de Ciencias Sociales realizado siete años más tarde se enfatizaba que los congresos son «verdaderos concilios de la inteligencia» que «tienen por finalidad inmediata, no la de resolver, de manera concluyente, los problemas que en ellos se planten [...] sino la de conocer opiniones autorizadas sobre esos problemas, sobre la manera de encararlos y sobre las distintas claves o fórmulas propuestas para su dilucidación», $R A C P$, XII (agosto 1916): 531. 
Centenario de la Revolución de Mayo, los congresos comenzaban a desarrollar lazos entre personas, conocimientos y experiencias de las diversas partes del mundo ${ }^{35}$. Así era expresado además en el discurso inaugural de Ernestina López: «el Congreso Femenino Internacional intenta echar un puente entre todas las mujeres de todas las posiciones sociales, entre las obreras de todos los gremios, entre las que trabajan en el silencio del hogar y en la acción militante de las asociaciones $\gg{ }^{36}$. Las diferentes lenguas no serían un obstáculo para las comunicaciones pues se dispuso que se hablara en castellano, francés, italiano, alemán, inglés y ruso; y conscientes de que ello podía convertirse en una limitación se estableció la presencia de intérpretes. De acuerdo con la lectura de las actas del Congreso los problemas sobre la participación de las mujeres en el mercado de trabajo estuvieron presentes en todas las secciones desde diferentes ángulos ${ }^{37}$.

De acuerdo con el examen de las actas del Congreso realizado cuando la Argentina festejaba el Centenario de la Revolución de Mayo, muchas mujeres universitarias habían establecido redes y publicaciones y organizaron reuniones como espacios privilegiados para el debate. Aunque el Congreso fue constituido por las universitarias, no estuvo cerrado a la intervención de aquellas que no habían transitado esos claustros, ya que participaron en la organización y con disertaciones algunas egresadas de escuelas normales - otro gran territorio para la circulación de ideas - y la trabajadora y militante socialista Carolina Muzilli. Ella presentó una comunicación sobre el divorcio y las propuestas del Centro Socialista Femenino de Buenos Aires fueron aprobadas luego de intercambiar opiniones. En las proposiciones aprobadas se unían reclamos por derechos políticos (sufragio universal para ambos sexos), civiles (divorcio absoluto) y laborales y sociales (treinta y cuarenta días de descanso antes y después del parto con goce de sueldo completo para proteger la maternidad, asiento para las vendedoras de tiendas, fábricas y talleres, inspección y vigilancia estricta para que se cumpla la ley que reglamenta el trabajo femenino e infantil y el fomento de escuelas profesionales para mujeres).

Finalmente, aunque en este punto me interesa el conocimiento que se adquiere en la universidad, quiero destacar también que sobre los debates de las congresistas, en el que participó junto a otras feministas Elvira López, se informó en las páginas de diarios como La Prensa y La Nación y en una revista ilustrada de amplia circulación como Caras y Caretas. Estas

35 Entre el 17 y el 23 de mayo de 1910 se realizó también en Buenos Aires el XVII Congreso Internacional de Americanistas.

36 Ibidem: 59.

${ }^{37}$ Ibidem: 58. 
publicaciones tienen que ser entendidas como mediadoras entre diferentes enunciaciones culturales que hablan de una compleja red de circulación de discursos impresos e ideas sobre lo social, pues no quedaban encerradas en los estrechos círculos universitarios.

\section{EL CAMPO MILITANTE: SABERES Y TRABAJO FEMENINO}

Si los espacios universitarios fueron propicios para la circulación de ideas, el campo militante constituye otro pilar importante de la difusión de conocimientos y prácticas sobre temas privilegiados por el debate sobre la cuestión social. El espectro de sujetos susceptibles de ser estudiados dentro de este campo es amplísimo. Sin embargo voy a recortar la figura de Carolina Muzilli, primero por su condición de mujer-militante-socialista $\mathrm{y}$, en segundo lugar, porque se trata de una joven perteneciente a una familia obrera que, aunque había realizado estudios secundarios, no había transitado los caminos de la educación superior como Elvira López y otras figuras femeninas militantes.

Ana Lía Rey ha señalado que Alfredo Palacios y Gabriela Lapèrrière de Coni fueron los oficiantes de Muzilli en un «sacerdocio laico» ejercido entre la acción y la pedagogía. La idea es interesante porque esta investigadora señala además que se establece un diálogo mediante el cual se «transmiten saberes». Además, la circulación de conocimiento cruza las fronteras de la academia y se establecen conversaciones entre intelectuales-militantes y militantes a través de una vasta red de publicaciones y de intervenciones públicas.

Uno de esos espacios privilegiados para la circulación de nociones sobre la explotación de la mujer, la solidaridad, la acción colectiva y los derechos fue la prensa obrera. Ella, ya sea la de origen gremial o de carácter ideológico, sirvió como tribuna de la palabra escrita. Había modos de transmitir los mensajes, recursos que se privilegiaban y, sobre todo, un interés claramente expresado de «iluminar» las conciencias ${ }^{38}$. Carolina Muzilli participaba de ese mundo militante que privilegiaba la escritura y que consideraba a la lectura como «foco de luz» y como «bandera de combate». Los trabajadores, mujeres $\mathrm{y}$ varones, le dieron forma a diversas publicaciones, las sostuvieron con su trabajo y sus aportes monetarios y las utilizaron para informar, educar, concientizar y denunciar las injusticias. Por eso es posible seguir las rutas de las ideas en periódicos como La Vanguardia o en Tribuna Femenina. Además, la edición de folletos «militantes» que se repartían gratuitamente o a precio reducido favorecía la difusión capilar de modos diferentes de pensar el mundo

${ }^{38}$ Lobato, 2009. 
social. Muchos de esos temas fueron tomados por otro tipo de publicaciones que tuvieron gran circulación, en las grandes ciudades principalmente, como la ya mencionada Caras y Caretas.

Como he analizado en otro trabajo, la gran cantidad de publicaciones e imágenes (fotografías y postales) que circularon entre fines del siglo XIX $\mathrm{y}$ principios del XX en las grandes ciudades argentinas de Buenos Aires y Rosario y en la uruguaya de Montevideo no sólo contribuyeron a configurar rasgos importante de una identidad nacional, cuyo componente básico fue la imagen del gaucho y lo criollo $^{39}$, sino que también ayudaron a conformar el comportamiento amoroso, los sentimientos y las emociones de las clases populares ${ }^{40}$. Sin embargo, esos folletos formaron parte también de la crítica social y aún no han sido suficientemente examinados como fragmentos de un espacio más amplio de circulación de ideas. Sólo como ejemplo basta mencionar que la rica colección de folletos, fotografías y postales coleccionadas por el antropólogo alemán Robert Lehmann-Nitsche contiene títulos como «Almas humildes. Versos dedicados a los trabajadores» (1913), «El matrimonio civil. El concubinato y la defensa de la mujer» (1888), «El cancionero revolucionario» (1909), «Las grandes huelgas de inquilinos. Los últimos sucesos sangrientos» (1907), además los más conocidos sobre la prostitución en Buenos Aires. De modo que estudiar los caminos de las ideas requiere de una mirada más amplia sobre los diferentes espacios y ámbitos por los que circulaban.

El campo militante tuvo un lugar privilegiado para la transmisión de conocimientos: las conferencias. Ellas se realizaban en locales partidarios, de asociaciones sindicales y de mujeres, en las bibliotecas públicas y populares y a ellas se asistía para escuchar las «verdades» sobre un tema o para presenciar el combate de palabras ${ }^{41}$. El verbo encendido de algunos conferenciantes congregaba a quienes encontraban en la palabra dicha y actuada el vehículo fundamental para transmitir las ideas de cambio social y político. Carolina Muzilli participó en las conferencias dadas por Gabriela Laperrière de Coni, donde hablaba sobre el mundo del trabajo femenino que ella conocía bien ${ }^{42}$.

Laperrière había llegado de Francia y se había convertido en militante socialista. Fue designada inspectora de fábricas y talleres en la ciudad de Buenos Aires, y en ese carácter recorrió los establecimientos industriales. Como resultado presentó un proyecto en 1902 para legislar sobre el trabajo femenino e infantil. Luego el diputado socialista Alfredo Palacios lo presentó

\footnotetext{
39 Prieto, 1988. Laera, 2003.

40 Lobato, 2011.

41 Barrancos, 1996. Suriano, 2001.

42 Rey, 2009: 5.
} 
al Congreso Nacional y se convirtió en ley, aunque con modificaciones provenientes del tratamiento parlamentario ${ }^{43}$. Ambas propuestas le asignaban a la maternidad presente y futura de la «obrera» gran importancia. La preocupación por el trabajo femenino e infantil era compartida con otras militantes socialistas y de otras ideologías como algunas anarquistas, el sindicalismo y el comunismo. Era un tema recurrente en los periódicos gremiales, en revistas como Vida Femenina, en las notas periodísticas de los diarios La Prensa y Crítica, en la ya mencionada Caras y Caretas y hasta en revistas comerciales de entretenimiento como Para Ti, de la editorial de Constancio C. Vigil.

La denuncia sobre las pésimas condiciones de trabajo de mujeres y niños y sobre los estragos que el exceso de labores y los bajos salarios causaban en el cuerpo de la obrera madre era un elemento compartido por las diversas ideologías de la época. Se mostraba que las pobres obreras madres tenían que ir al trabajo descuidando a sus hijos, que los niños que trabajaban estaban obligados a abandonar la escuela, que la alimentación era deficiente, que el abuso era una constante. Había en las páginas de algunas publicaciones valoraciones distintas para las labores femeninas, dependía del lugar en que se realizara y de la actividad que se desplegara.

Carolina Muzilli tuvo como meta conocer para cambiar la sociedad en la que vivía, y como su maestra Gabriela Laperrière de Coni dictó conferencias, escribió en la prensa socialista, en particular en La Vanguardia y participó en diversos congresos. Para ella el estudio de las estadísticas sociales era fundamental. Así señalaba que «es indudable que no se puede realizar obra de elevación social en las tinieblas» (p. 14). Para poder salir de la oscuridad y la confusión era necesario «comprobar las condiciones en las que vive el pueblo que trabaja» (p. 16). Conocer e iluminar fueron palabras plenas de sentido que tenían la función de orientar las prácticas discursivas militantes. Las ideas de la ilustración se habían difundido ampliamente en los territorios americanos, y el peso de los conocimientos y de la razón era reconocido por sectores de las elites políticas e intelectuales como por sus críticos.

Para conocer, Carolina Muzzili consideraba las estadísticas como un medio, por eso pensaba que en la Argentina no se conocían los beneficios que este conocimiento producía pues para ello se necesitaban «[...] hombres que, como Alfredo Nicéforo, el admirado maestro, desciendan al terreno experimental, a fin de comprobar las condiciones en las que vive el pueblo que trabaja y sufre» (p. 16). El recurso de considerar la cita pone en evidencia que Carolina conocía el trabajo del estudioso italiano, quien había logrado un gran dominio de la estadística y que se había desempeñado en varias

${ }^{43}$ Lobato, 2000; 2006; 2007. 
universidades europeas como la de Bruselas, Lausana o Roma. Para ella «El ilustre Nicéforo en su libro sobre antropología de las clases pobres Forza e Richeza, demuestra como el estudio de las enfermedades sociales y todo lo que atañe a la clase trabajadora, para ser eficaz, debe hacerse no desde un cómodo gabinete de trabajo, muellemente sentados en un sillón, sino actuando en el campo experimental, es decir confundiéndose, viviendo si es posible, a ratos, la vida de los estudiados, esto es, investigado directamente». Al rigor de las estadísticas agregaba la experimentación y la «investigación» en el campo para tener un conocimiento riguroso de la condición obrera en general y del trabajo femenino en particular.

En rigor de verdad las estadísticas se habían planteado como necesarias también para el Estado cuando desde la segunda mitad del siglo XX comenzaron a realizarse censos nacionales que buscaban realizar un relevamiento numérico de la población. El objetivo era construir estadísticas, universales, centralizadas, simultáneas (debían realizarse en todo el territorio al mismo tiempo), basadas en la individualización de quiénes eran los actores de la vida social, económica y cultural. Como han señalado algunos estudiosos, las estadísticas contribuyeron a constituir una idea de la nación porque favorecía la auto-identificación colectiva de cada país y la diferenciación y comparación con los otros estados ${ }^{44}$. Se podría sostener que es una de las marcas, aunque este rasgo no fue exclusivo de la Argentina sino que se constituyó en una característica del pensamiento estadístico, pues es reconocible también en otros países americanos (Estados Unidos y Chile ubicados en los extremos del mapa americano) así como en Europa (Francia, Italia). Sin embargo las estadísticas sociales tal como reclamaba Muzilli recién cobraron vida cuando el Departamento Nacional del Trabajo comenzó a realizar investigaciones de modo más sistemático sobre cuestiones sociales. Por eso puede afirmarse que estas informaciones contribuyeron también a reconocer, recortar y definir a los actores sociales, en particular a los trabajadores, y también a establecer diferencias de género y generacionales más precisas en la década del diez del siglo $\mathrm{XX}^{45}$. Para la década del treinta la estadística sociolaboral ya formaba

${ }^{44}$ Otero, 1997-98: 125. García Bollo, 1999.

45 La extensión de la idea de que el conocimiento de las condiciones de las diferentes clases sociales y de lo que sucede en otros países hace que la acción social sea «más vinculada, armónica y económica» puede seguirse en el artículo publicado en la Revista Argentina de Ciencias Políticas por Francisco Netri, quien fue presidente de la Federación Agraria Argentina y director del periódico La Tierra. Aunque el tema es la desocupación, no deja de lado que esta impacta sobre «los trabajadores y trabajadoras de la industria», se refiere también al personal doméstico en su mayoría femenino. Si el modelo es la «sociedad Humanitaria» de Milán me interesa destacar que una de las soluciones que se plantea es la instrucción profesional. Se 
parte del lenguaje de las instituciones laborales, de las organizaciones obreras y de las organizaciones patronales ${ }^{46}$.

Como acabo de mencionar, un organismo estatal como el Departamento Nacional del Trabajo también buscó conocer las condiciones de vida y de trabajo, realizó investigaciones de carácter etnográfico y las usó como base para pensar propuestas legislativas ${ }^{47}$. Durante el período más activo en materia de producción de información, 1907-1930, no solo buscó establecer, reglamentar y vigilar el cumplimiento de las normas legales sino que también intentó ampliar las fronteras del conocimiento sobre el trabajo femenino al investigar sobre el trabajo asalariado en fábricas y talleres, el trabajo a domicilio y el servicio doméstico ${ }^{48}$. Como el conjunto de los estudios realizados por esta institución, las investigaciones del DNT conformaron un inmenso cuadro estadístico de la condición obrera en la Argentina hasta que el peronismo reorganizó la institución, modificó su denominación y la dotó de otras funciones ${ }^{49}$.

Del examen de esos informes surge también que para conocer y legislar en Argentina era fundamental saber qué sucedía en Bélgica, Australia, Nueva Zelanda o Estados Unidos. Un estudio minucioso de esos informes da cuenta de que los funcionarios del DNT estaban relacionados con los editores de la República Argentina de Ciencias Políticas, ya mencionada, y también con el Boletín del Museo Social Argentino. Que las notas, conferencias y publicaciones se divulgaban en diarios como La Prensa y La Nación. Un apropiado diagnóstico de los problemas, de la situación de los trabajadores (varones y mujeres) y de las leyes más adecuadas ocupó durante años al escaso número de funcionarios que lo integraron. Sin embargo otras figuras habían precedido en la tarea de investigar sobre las condiciones de trabajo de las clases laboriosas: en la ciudad de Buenos Aires, Gabriela Laperrière de Coni, la «maestra-modelo» de Muzilli, visitaba fábricas y talleres para realizar sus

\footnotetext{
destaca que esta sociedad «Proyectó una escuela profesional femenina e instituyó cursos de ciencias domésticas dirigidas a plasmar con relación a las exigencias de la vida moderna, la mujer y la madre obrera, haciéndola apta para gobernar en su casa, para que pueda sacar el mayor provecho posible de las modestas ganancias familiares y dando disciplina y reposo moral a la vida del trabajador» (32). También señala que «las instituciones de asistencia social y de instrucción ponen en contacto a hombres de ideas, orígenes, clases distintas, que en el campo concreto de determinados problemas a resolver, de actividades a explicar, de fines a alcanzar, se hallan ya concordantes en ideas, en intereses, en propósitos, tendencias...» (6). Artículo completo en Netri, X (abril, 1915): 5-33.

46 Daniel, 2012: 149-212.

47 Lobato, 2000; 2007. Soprano, 2000.

${ }^{48}$ Lobato, 2005.

49 Lobato 2007; 2010.
} 
informes. Por la época Pablo Storni y Adrián Patroni habían efectuado sendos informes sobre las industrias porteñas, y Juan Bialet Massé había sido designado por el gobierno para estudiar lo que sucedía en el mundo del trabajo del interior del país.

De modo que el conocimiento de las condiciones de trabajo de las mujeres y del conjunto de los trabajadores que Muzilli proponía formaba parte de un universo de saberes que circulaba en los medios universitarios, en los ámbitos gubernamentales y entre los militantes del partido Socialista. Ella dialogaba también con Alfredo Palacios quien había presentado la ley que proponía la protección del trabajo femenino e infantil y que fue aprobada en el Congreso Nacional en 1907. Palacios citaba a Kautsky y, a su vez, este era citado por Muzilli. El primero lo cita en La defensa de los trabajadores para referirse al trabajo de las mujeres y niños en Inglaterra y ella lo hace para enfatizar la importancia de la organización de las mujeres ${ }^{50}$.

En diciembre de 1912 Muzzili recibió una nota firmada por Emilio Frers y Tomás Amadeo, presidente y secretario del Museo Social Argentino solicitándole la «cooperación» para elaborar «informaciones estadísticas lo más completas posible» sobre:

Número de mujeres obreras en la Capital y en todo el país.

Fábricas en las cuales trabajan: industrias que las ocupan y en qué forma. Salarios.

Horas de trabajo.

Leyes que reglamentan ese trabajo.

Mejoras que se desearían obtener.

$\mathrm{Y}$ todo lo que de una $\mathrm{u}$ otra forma pudiera contribuir a la mejor documentación del interesante asunto referente a la mujer obrera en nuestro país.

[...] Los materiales que se reciban serán enviados a Bélgica [...] para figurar en la sección argentina de la exposición ${ }^{51}$.

La nota que le dirigieron las autoridades del Museo Social Argentino es interesante por varios motivos. En primer lugar implica un reconocimiento de la capacidad de la militante socialista para producir información. En segundo término de la intensa circulación de saberes entre personas e instituciones de posiciones políticas e ideológicas bien diferentes. Por último la relevancia que tuvieron las exposiciones y reuniones científicas como ámbitos de difusión y exhibición de saberes. Aunque las exposiciones fueron analizadas como

${ }^{50}$ Diario de Sesiones de la Cámara de Diputados, Año 1906, Sesiones ordinarias, Tomo I, Talleres Gráficos de la Penitenciaría Nacional, Buenos Aires, 1907: 797, y Carolina Muzilli, El trabajo femenino, Tralleres Gráficos Rosso y Cía, Buenos Aires, 1916: 6.

${ }^{51}$ La nota firmada por Frers y Amadeo se encuentra en Muzilli, 1916. 
«galerías del progreso» y como «espectáculo expositor» de objetos visuales ${ }^{52}$, también pueden considerarse como vitrinas de saberes. En la Exposición Universal de Gante de 1913, el Museo Social Argentino exhibió información social sobre la República Argentina ${ }^{53}$. Eran «objetos» que escapaban del modelo tradicional de bienes producidos en un país como carne y cereales ${ }^{54}$.

Carolina Muzilli fue convocada para generar la información necesaria sobre trabajo femenino que se exhibiría junto con estadísticas del DNT y fotografías, entre las que se destacan las de las escuelas del país. Junto a ella colaboraron Elvira López y Alfredo Palacios. El lugar de las exposiciones y el rol de la economía y de la estadística social y de la «cuestión de la mujer» y el lugar que ocupaban algunas mujeres requiere de mayores investigaciones, pero para comprender la importancia de la constitución de esas redes para la circulación de ideas se puede agregar que Ernestina López, hermana de Elvira, otra de las cuatro primeras doctoras egresadas de la Facultad de Filosofía y Letras, formó parte de los comités especiales que se constituían en estas ocasiones y participó como delegada de la Junta de Educación en la Exposición de Saint Louis en 1904. Carolina Muzilli fue premiada por su trabajo y en 1915 participó de la exposición Internacional de Chicago.

El trabajo fue publicado bajo la forma de folleto en 1916. Allí su autora retoma un tema enunciado por diferentes tribunas ideológicas: el de la obrera madre. Señala: «he pensado cuán grande es la misión de estas mujeres que contribuyen a la producción y que no descuidan su tarea primordial: la de ser madres» ${ }^{55}$. En la «Emancipación de la mujer», un artículo publicado en $L a$ Vanguardia, había afirmado años antes: «En la obra de emancipación de la mujer es necesario trabajar para arrancar de las fábricas malsanas a la mujer madre y futura madre» ${ }^{56}$. Si el feminismo es un movimiento político que encarna la lucha por el mejoramiento de la vida de las mujeres en todos los órdenes la preocupación por la mujer obrera no debía estar al margen según su perspectiva. Por eso arremete con lo que definía como el «feminismo burgués» más preocupado por la igualdad civil y política ${ }^{57}$. Si la importancia de la mujer en la familia constituye un punto compartido por la militancia feminista (salvo rara excepciones), si la educación y «elevación moral de las mujeres» constituía una enunciación usual en la época, si se planteaba que

52 González Stephan y Andermann, 2006: 10-11.

${ }^{53}$ Sobre la exposición Universal de Gante y el rol del Museo Social, véase $R A C P, \mathrm{~V} / 28$ (enero 1913):489-491.

${ }_{54}$ Becerra, 2009: 209-238.

55 Muzilli, 1916: 5.

${ }_{56}$ La Vanguardia (Buenos Aires, 26 de septiembre de 1910).

${ }^{57}$ La Vanguardia (Buenos Aires, 26 de septiembre de 1910 y 17 de enero de 1912). 
el trabajo femenino debía ser remunerado en igualdad con los hombres en la mayoría de los casos, había otros debates sobre la «cuestión de la mujer» que no concitaban acuerdos y que dividieron muchas veces al campo feminista ${ }^{58}$.

Cabe agregar que la protección del trabajo femenino e infantil ya era objeto del debate internacional. Por ejemplo, la prohibición absoluta de las labores en horario nocturno fue planteada en el Congreso de Berna en 1906 y ratificada en la Carta Internacional del Trabajo de Berna en 1913. Ambas eran considerablemente citadas por los abogados que se desempeñaban en el Departamento Nacional del Trabajo así como en otros países americanos. En Uruguay fue otra militante socialista, Paulina Luisi, quien contribuyó a difundir algunas de estas ideas en ese país.

\section{SABERES EN MOVIMIENTO: UN EPÍLOGO}

He planteado a lo largo de estas páginas el lugar de los circuitos universitarios para la circulación de ideas de lo «social» y sobre su específica y particular visión sobre las condiciones de vida y de trabajo de las mujeres. Circuitos de difusión y redes de individuos ampliaron los contornos del debate sobre la participación femenina en el mundo del trabajo. Estaciones importantes de esa peculiar interacción entre las rutas de las ideas y sus vehículos, como las publicaciones, las cátedras universitarias y los congresos, se unieron a las prácticas institucionales, ya sean aquellas de las organizaciones de la sociedad civil como las del estado, para conocer la magnitud y las características de esa participación, pero también para plantear algunas soluciones que iban desde la organización gremial para ampliar las demandas por derechos hasta la protección de los sectores considerados más desprotegidos y vulnerables. Como han mostrado varios estudios recientes en el campo académico, a partir de esas acciones se consolidaron ciertos estereotipos laborales para las mujeres, y también para los varones, y se fortaleció la imagen de la obrera madre como primordial.

Como he analizado en las páginas precedentes, las ideas que permitían un diagnóstico sobre la situación de «la mujer trabajadora» se pronunciaron desde las cátedras universitarias o desde las tribunas militantes y fueron entrecruzándose y separándose, conformando una red mucho más amplia que la de los estrechos círculos universitarios. La recepción de algunos libros, desde Stuart Mill y Mary Wollstonecraft a Kautsky, Nicéforo y Menger, pasando por

${ }^{58}$ Para un análisis sobre feminismo, diferencia sexual e igualdad de derechos, veáse Nari, 1995. 
los más frecuentemente estudiados en las historias del pensamiento argentino como Spencer, Comte, Lombroso y Le Bon, así como la cita que legitima y autoriza la palabra especializada, muestran que, al menos en la Argentina de principios del siglo XX, se estaban construyendo ámbitos por donde se desplazaban saberes sobre problemas sociales que están marcados por las diferencias entre mujeres y varones y que, en algunos casos, se convirtieron en hegemónicos, aunque el punto de partida de esas miradas fuera diferente. $\mathrm{He}$ elegido el punto de vista de Elvira López y de Carolina Muzilli junto con el de Ernesto Quesada porque representan no solo relatos interrelacionados, sino que constituyen una compleja trama de relaciones entre sujetos y comunidades diferentes, incluso en términos de su poder. Pero también porque muestran que, en la contienda discursiva de la época, las mujeres, aunque no ocupaban la escena, tampoco estaban totalmente al margen. Producían conocimientos que luego utilizaban en sus demandas.

La circulación de saberes sobre «cuestión social» y «cuestión de la mujer» nos advierte sobre la importancia de pensarlos como «saberes situados», pues algunas ideas se transforman localmente. Sin embargo en este texto no he avanzado en una dirección que me permita pensar múltiples direcciones en el viaje de esas ideas. Lo que sí se puede afirmar es que en la Argentina de las primeras décadas del siglo XX se traducían ciertas nociones para generar dispositivos de diagnóstico que permitieran a su vez generar políticas sociales para proteger a las mujeres obreras, pero también a los trabajadores en su conjunto. En este punto se puede afirmar que la «cuestión de la mujer» se ligó a la «cuestión social» y se amalgamó con las ideas que circulaban por las rutas del feminismo.

Además, las palabras pronunciadas en las conferencias orales se propagaban a su vez en la prensa diaria porteña, tanto en la comercial como en la obrera y socialista. Se publicaban los resúmenes de las exposiciones, y con ello no sólo se informaba sino que también se generaba cierto interés en públicos lectores más amplios. Como he mencionado también, los temas sociales fueron tomados por publicaciones denominadas «populares» que se dirigían a un público masivo. Entonces se ampliaban las fronteras de los conocimientos, de la información y de la sensibilidad hacia los temas sociales. Como se dijo en el Congreso Femenino Internacional, se construían puentes entre diferentes saberes, pero también entre las mujeres de todas las clases sociales, entre las obreras de fábricas y talleres, entre las que trabajan en el hogar y entre las militantes y participantes de diferentes asociaciones. 


\section{BIBLIOGRAFÍA}

Altamirano, Carlos, «Entre el naturalismo y la psicología: el comienzo de la "ciencia social" en la Argentina», Federico Neiburg y Mariano Plotkin (comps.) Intelectuales y expertos. La constitución del conocimiento social en la Argentina, Buenos Aires, Paidós, 2004: 31-66.

Barrancos, Dora, «Cien años de estudios feministas en la Argentina», Mora, 8 (Buenos Aires, 2002).

Barrancos, Inclusión/Exclusión, Historia con mujeres, Buenos Aires, FCE, 2001.

Barrancos, La escena iluminada. Ciencias para trabajadores, 1890-1930, Buenos Aires, Plus Ultra, 1996.

Becerra, Malena, «La economía social argentina en las exposiciones internacionales. La exhibición del Museo Social Argentino en la exposición internacional de Gante (1913), María Silvia Di Lisia y Andrea LLuch (eds.), Argentina en exposición, Ferias y exhibiciones durante los siglos XIX y XX, Sevilla, CSIC, 2009: 209-238.

Botana, Natalio R., El orden conservador. La política argentina entre 1880 y 1916, Buenos Aires, Sudamericana, 1985.

Buchbinder, Pablo, Los Quesada. Letras, ciencias y politica en la Argentina, 18501934, Buenos Aires, Edhasa, 2012.

Carreras, Sandra, «Spengler, Quesada y yo...», Intercambio intelectual y relaciones personales entre la Argentina y Alemania, Eugenia Scarzanella y Mônica Risa Schpun (eds.), Sin fronteras. Encuentros de mujeres y hombres entre América Latina y Europa (Siglos XIX-XX), Madrid, Biblioteca Ibero Americana-Vervuert, 2008.

Daniel, Claudia, «Las estadísticas en la construcción del Estado social (1930-1943)», Carolina Biernat y Karina Ramaciotti, Politicas sociales. Entre demandas y resistencias, Argentina, 1930-1970, Buenos Aires, Biblos, 2012.

Femenías, María Luisa (comp.), Perfiles del feminismo iberoamericano, Buenos Aires, Catálogos, 2005.

González Bollo, Hernán, «Ciencias sociales y sociografía estatal. Tras el estudio de la familia obrera porteña, 1899-1932», en Estudios sociales, 16 (1999): 19-39.

Laera, Alejandra, El tiempo vacío de la ficción. Las novelas argentina de Eduardo Gutiérrez y Eugenio Cambaceres, Buenos Aires, Tierra firme-FCE, 2003.

Lobato, Mirta Zaida, «Instituciones laborales, funcionarios y política: notas a partir de un proyecto de investigación», Revista de Trabajo, 6/8, Ministerio de Trabajo, Empleo y Seguridad Social (Buenos Aires, 2010): 105-108.

Lobato, «Te amo, te odio, te quiero: una aproximación a la cultura afectiva de las clases populares en el Río de La Plata, 1880-1930», Gloria B. Chicote y Bárbara 
Göbel (eds.), Ideas viajeras y sus objetos: el intercambio cientifico entre Alemania y América Austral, Madrid, Iberoamericana-Vervuert, 2011: 339-349.

Lobato, Historia de las trabajadoras en la Argentina (1869-1960), EDHASA, Buenos Aires, 2007.

Lobato, «Historia de las instituciones laborales en Argentina: una asignatura pendiente», Revista de Trabajo, 3/4 (2007) Nueva época, Órgano oficial del Ministerio de Trabajo, Empleo y Seguridad Social: 145-156.

Lobato, «El estado y el trabajo femenino: el Departamento Nacional del Trabajo», Daniel Lvovich y Juan Suriano, Las políticas sociales argentinas en perspectiva histórica, Prometeo, Buenos Aires, 2006.

Lobato, «Entre la protección y la exclusión. Discurso maternal y protección de la mujer obrera, Argentina, 1890-1934», Juan Suriano (comp.), La cuestión social en argentina, 1870-1943, Buenos Aires, Editorial La Colmena, 2000.

Lobato, «El movimiento feminista y la situación de la mujer en las palabras de Elvira López», en Mora, 8 (2002).

López, Elvira, El movimiento feminista. Tesis presentada para optar al Grado de Doctora en Filosofía y Letras, Buenos Aires, Universidad de Buenos Aires, Tesis 83-7-39, 1901.

Muzilli, Carolina, El trabajo femenino, Buenos Aires, Talleres Gráficos Rosso y Cía, Buenos Aires, 1916.

Nari, Marcela, «Feminismo y diferencia sexual. Análisis de la «Encuesta Feminista Argentina» de 1919», Boletín del Instituto de Historia Argentina y Americana Dr. Emilio Ravignani, 12, (II semestre de 1995): 61-86.

Prieto, Adolfo, El discurso criollista en la formación de la Argentina Moderna, Buenos Aires, Sudamericana, 1989.

Quesada, Ernesto, La cuestión femenina. Discurso pronunciado en el acto de clausura de la exposición femenina en el Pabellón Argentino, Buenos Aires, Imprenta de Pablo Coni, 1899.

Quesada, Ernesto El feminismo argentino. Tendencias y orientaciones. Conferencia dada en el Consejo Nacional de Mujeres 24 de junio de 1920, Buenos Aires, Talleres Gráficos de Rosso y Cía, 1920.

Roldán, Darío (comp.), Crear la democracia. La Revista Argentina de Ciencias Politicas y el debate en torno de la República Verdadera, Buenos Aires, FCE, 2006.

Rey, Ana Lía, «Carolina Muzilli, entre la militancia socialista y la obstinación autodidacta. Intervenciones a través del diario socialista La Vanguardia», Segundas Jornadas Nacionales de Historia social, 13, 14 y 15 de mayo de 2009, La FaldaCórdoba, mimeo. 
Soprano, Germán, «El Departamento Nacional del Trabajo y su Proyecto de Regulación Estatal de las Relaciones Capital-Trabajo en Argentina, 1907-1943», José Panettieri (comp.), Argentina: trabajadores entre dos guerras, Buenos Aires, Eudeba, 2000.

Spadaro, María, «Elvira López y su tesis "El movimiento feminista (1901) educación de las mujeres camino hacia una sociedad más justa"», Mora, 8 (2002).

Suriano, Juan, Anarquistas. Cultura y política libertaria en Buenos Aires 1890-1910, Buenos Aires, Manantial, 2001.

Terán, Óscar, Vida cultural en el Buenos Aires fin-de-siglo (1810-1910), Buenos Aires, FCE, 2000.

Terán, Óscar, Ideas en el siglo. Intelectuales y cultura en el siglo XX latinoamericano, Buenos Aires, Siglo XXI Editores Argentina, 2004.

Zimmermann, Eduardo, Los liberales reformistas. La cuestión social en la Argentina, 1890-1916, Sudamericana, Buenos Aires, 1994.

Fecha de recepción: 6/10/12

Fecha de aceptación: 9/1/13

\section{The route of the ideas: «Social Question», feminisms and female labor.}

In this article I analyze the voices that enable us to unravel the setup of a series of political and social concerns whose nucleus consists in what women who work do or don't do, and in how the ideas on feminisms and related social issues took shape \& form. Specifically, I focus on the personalities of Ernesto Quesada, an intellectual from the generation of 90's, Elvira López, author of the first thesis on the feminist movement written in 1901 at the Faculty of Philosophy \& Arts of the University of Buenos Aires, and Carolina Muzilli, a socialist militant. This allows me to think about heterogeneous spheres of action and means of intervention as well as using and circulating written words associated with the ideas about social problems.

KeY words: Feminisms; Social issues; Women's work; Social history; Cultural history. 